\title{
A reorientação da ação pedagógica na Educação Física sob a perspectiva da inclusão: a pesquisa-ação como caminho
}

\author{
Gisele Cristina de Souza* \\ Santiago Pich ${ }^{* *}$
}

\begin{abstract}
Resumo: O artigo aborda a inclusão escolar na Educação Física, sob o referencial teórico do estigma da pessoa com deficiência. O objetivo foi orientar o processo de reconstrução das práticas pedagógicas do professor na implantação da Educação Física inclusiva. Adotamos a abordagem qualitativa com proposta de trabalho na pesquisa-ação, sendo que, a análise de conteúdo resultou em três categorias: o legado da formação inicial e continuada sobre a inclusão; o rendimento esportivo e o desenvolvimento motor "normal", e, o sistema de avaliação do componente curricular Educação Física e as reorientações da prática pedagógica.
\end{abstract}

Palavras-chave: Educação Física escolar. Inclusão. Prática Pedagógica. Pesquisa-ação.

\section{INTRODUÇÃo}

Na década de 80 do século XX, no Brasil surgiu oficialmente, no bojo das políticas públicas emanadas da Constituição de 1988, o marco do movimento de inclusão escolar das crianças com deficiência na escola regular. Os dados estatísticos atuais revelam a dificuldade de adesão à inclusão no ensino regular, pois há discrepância entre o número de matrículas de crianças com deficiência na escola regular e aqueles que efetivamente a frequentam, como apresenta Antunes (2006, p. 17)

\footnotetext{
"Fisioterapeuta, Itajaí, SC, Brasil. E-mail: gcsfisio@hotmail.com

"Professor do EED/UFSC, Florianópolis, SC, Brasil. E-mail: santiago.pich@yahoo.com.br
} 
a organização Mundial de Saúde estima que cerca de $10 \%$ da população terrestre possui necessidades especiais - cerca de 600 milhões de pessoas - e dados estatísticos brasileiros recentes, [...] alertamnos para a existência de 358.987 alunos especiais matriculados [...]. Destes alunos, apenas 144.543 frequentavam salas regulares.

Os dados supracitados projetam a dificuldade de garantir o acesso e a permanência de toda criança indiscriminadamente, na escola comum. Mediante esta dificuldade para a operacionalização da inclusão, apontamos a necessidade da pesquisa social, como forma de contribuir para a construção das condições educacionais para a efetivação da inclusão na escola. Assim, delimitamos o objeto deste estudo: a reorientação da prática pedagógica dos professores de Educação Física na perspectiva da inclusão escolar a partir da pesquisa-ação ${ }^{1}$.

Segundo Sassaki (1997) inclusão é um conjunto de procedimentos para a adequação do sistema educacional geral às necessidades, habilidades e aspirações dos alunos com e sem deficiência, os quais devem ser aceitos com as suas diferenças, pois elas nos fazem seres humanos únicos. Neste sentido compreendemos que a educação inclusiva é aquela acessível para todas as crianças, com e sem deficiência, contudo o recorte do objeto deste estudo destinou-se à inclusão do aluno com deficiência na escola regular.

A nossa principal sustentação teórico-metodológica é a teoria do estigma do sociólogo Erving Goffman. Para ele: "estigma é a situação do indivíduo que está inabilitado para a aceitação social plena". (GOFFMAN, 1988, p. 7). Ainda, ele aponta três tipos de estigma: a rejeição às deformidades físicas; a culpa de caráter individual (como o vício), e, por último, os estigmas tribais de raça, nação e religião. Delimitamos o recorte do conceito do estigma

\footnotetext{
'Salientamos que a nossa opção pela pesquisa-ação foi motivada pela tentativa de canalizar uma expectativa presente nos relatos dos professores de Educação Física da rede municipal, quando visitados pelos profissionais do órgão responsável pelo acompanhamento nas escolas das PcD por processos de formação em torno da inclusão escolar.
} 
relacionado à rejeição de deformidades, pois este se relaciona a manipulação deteriorada da identidade do aluno com deficiência na escola.

Atentos à descrição de Goffman a respeito do conceito de estigma e as notas sobre a diferença (da deficiência) como um valor à diversidade social; destacamos as condições que contribuem para proporcionar à pessoa com deficiência $(\mathrm{PcD})$ estigmatizada os critérios reais de identificação social. Diante disso, relatamos que a deficiência é um conceito moderno, que emergiu após a sociedade enfatizar a eficiência como marca da vida. Puppin (1999) aponta para a deficiência a criação de uma identidade social, postulando a PcD como o diferente que não é eficiente.

Goffman (1988) propõe que a sociedade nas suas relações estabelece noções para categorizar as pessoas, representando concepções de normativas e exigências numa identidade social virtual, desconsiderando os atributos pessoais reais, ou seja, sua identidade social real. $\mathrm{O}$ autor coloca que na determinação da categoria social nem todos os atributos estão presentes, a sociedade observa apenas aqueles que são incongruentes com a expectativa de eficiência social, ou seja, as diferenças.

Nesse sentido as diferenças são as características que a sociedade utiliza para representar a PcD como aquele que está fora das expectativas de produção social, colocando-o na categoria de não-eficiente (deficiente). As diferenças são então concebidas como as atribuições pessoais que constituem a identidade social virtual, desconsiderando quaisquer outros atributos que não o coloquem na categoria de deficiente.

Dotados deste marco teórico, compreendemos que a escola regular deve ser o espaço em que se realiza o sentido de inclusão e aceitação social plena da pessoa com e sem deficiência, almejando o desenvolvimento integral de cada sujeito. Ainda, segundo Mantoan (2003) na maioria das escolas brasileiras a inclusão implica em inovar esforços de modernização e de reestruturação das condições atuais de ensino e do modo como o ensino é ministrado. 


\section{ArtigosOrignais}

Adentrando no recorte deste estudo entendemos que a Educação Física é um componente curricular da escola regular, e deve participar de forma atuante e adjuvante no processo de inclusão escolar e social das PcD (AGUIAR; DUARTE, 2005). Porém, na atualidade a prática pedagógica da Educação Física pouco tem superado a organicidade escolar segmentalizada a fim de estabelecer uma prática verdadeiramente inclusiva.

O desenvolvimento da Educação Física como componente curricular possui a carga da determinação das estruturas macrossociais. Assim, a Educação Física escolar desenhou-se a partir de um caráter instrumental, no qual o modelo de corpo forte e sadio foi articulado em função da sociedade e do regime capitalista emergente no século XIX (CAPARROZ, 2007). Contudo, Bracht (1992) aponta que o tema da Educação Física não deve se restringir aos códigos ${ }^{2}$ do esporte, balizado no contexto macrossocial pela descoberta do atleta. O mesmo autor refere que a identidade da Educação Física na escola compreende uma reflexão do próprio papel da escola na sociedade.

Aguiar e Duarte (2005) sugerem o papel do professor de Educação Física na direção de uma abordagem de cooperação e participação na convivência com a diversidade, incluindo nos jogos e campeonatos escolares, todo o alunado, inclusive aquele que não demonstra talento ou que apresenta dificuldades no controle do corpo e dos movimentos.

Compreendemos que a inclusão se refere a uma Educação Física com o significado de educar para a diferença, para a convivência e a aceitação das diferentes configurações possíveis da corporeidade humana. No entanto, o professor está sujeito às atribuições do sistema escolar e o meio social que condicionam a prática pedagógica a se adequar aos códigos da instituição esportiva. Assim, a prática pedagógica dos professores de Educação Física

${ }^{2}$ Código é o que expressa/denuncia o sentido que está incorporado no condicionamento de determinado contexto (BRACHT, 1992). 
está substantivada pelos fundamentos da pedagogia de rendimento, por um lado, e tensionada pelo contexto da inclusão de Pcd, por outro.

O texto se estrutura apresentando em primeiro lugar os procedimentos metodológicos, prossegue com o desenvolvimento das categorias de análise, e finaliza com as considerações finais.

\section{Procedimentos metodológicos}

Neste estudo tomamos o referencial teórico dentro da abordagem qualitativa da pesquisa social. Adotamos a proposta de trabalho na pesquisa-ação, segundo a concepção e organização referida por Thiollent (1996). O autor aponta o planejamento da pesquisa-ação de forma flexível, sem estabelecer fases ordenadas; propondo o roteiro no qual há um ponto de partida (fase de exploração) e de chegada (divulgação dos resultados), sabendo que no desenvolvimento da pesquisa se articulam os passos do percurso e as ferramentas em função das circunstancias investigadas.

Participaram deste estudo sete professores de Educação Física efetivos na Rede Municipal de Ensino no município de Itajaí. O convite teve caráter intencional segundo a relevância que os professores representavam para o objeto de estudo: todos eles atuavam com turmas inclusivas. A participação teve caráter voluntário, e foi formalizada mediante assinatura do termo de consentimento livre e esclarecido conforme as considerações estabelecidas na Resolução 196/96 do Conselho Nacional de Saúde. O projeto de pesquisa foi avaliado e aprovado pelo Comitê de Ética em Pesquisa da Universidade do Vale do Itajaí (UNIVALI) ${ }^{3}$.

Para a coleta dos dados nos valemos de diversos instrumentos, que foram sendo readequados ao longo do processo. Desta forma, realizamos observações livres das aulas dos professores participantes registradas em diários de campo. Ao longo da pesquisa foram realizadas oficinas, seminários, e, no final, dois encontros pautados

${ }^{3}$ Parecer no $178 / 10$ em 25/06/2011.

Movimento, Porto Alegre, v. 19, n. 03, p. 149-169, jul/set de 2013. 


\section{4}

ArtigosOriginais Gisele Cristina de Souza, Santiago Pich

nos critérios do grupo focal. Todas essas atividades também foram registradas em diários de campo. A seleção das temáticas das oficinas e seminários foi definida atendendo a demanda do grupo, iniciando, porém, com a discussão conceitual da inclusão.

Para o procedimento de análise de dados adotamos a análise de conteúdo proposta por Bardin (2004). No procedimento de análise interpretamos duas categorias para explicitar o objeto deste estudo: o legado da formação inicial e continuada sobre a inclusão; o rendimento esportivo e o desenvolvimento motor "normal", e, o sistema de avaliação do componente curricular Educação Física e as reorientações da prática pedagógica.

\section{LEGADO DA FORMAÇÃO INICIAL E CONTINUADA SOBRE A INCLUSÃO}

Diante da análise, o conteúdo evidenciou que a formação inicial dos professores não implicava em propostas inclusivas, e apresentou uma concepção de Educação Física pautada pelos códigos da instituição esportiva. No entanto, o grupo de professores apontou que foi na graduação que tiveram o primeiro contato com a inclusão, mas que o conteúdo não dava suporte a uma prática pedagógica condizente. Nesse sentido, apresentamos os comentários dos professores participantes: "Na graduação foram realizados muitos estágios com equipes de rendimento e muitos possuíam limitações físicas, intelectuais, visuais e auditivas." (professor João ${ }^{4}$ na Oficina em 13/08/2010). Os dados empíricos demonstram que o referencial inclusivo não foi explorado na formação inicial, e, além disso, se constata a presença do conteúdo orientado pelo rendimento físicoesportivo, característico da formação tradicional-esportiva (BETTI; BETTI, 1996).

Para complementar os dados da análise, também destacamos, a seguir, as primeiras experiências inclusivas da vida docente dos professores, pois, ouvimos que as dificuldades eram muitas, e nem

${ }^{4}$ Todos os nomes utilizados são fictícios.

Movimento, Porto Alegre, v. 19, n. 03, p. 149-169, jul/set de 2013. 
todas as aulas eram inclusivas. Geralmente os professores focavam no aluno com deficiência, não conseguindo "encontrar resultados", como escutamos na fala desta professora:

Contra as regras do sistema onde não se aceitava certa deficiência por desconhecê-la... Aos trancos e barrancos, sem conhecimento prévio, baseada apenas na convivência diária e adequação a linguagem do aluno, ele fez parte dos jogos escolares contra a vontade de muitos e ajudou a trazer o título com muita eficiência, o que me trouxe profissionalmente muita satisfação (Professora Mariane na Oficina em 13/08/2010).

A primeira experiência inclusiva da professora aponta que a inclusão só ocorreu a partir da adesão do aluno com deficiência aos códigos da instituição esportiva. E ainda denota que a professora incluiu o aluno nos jogos escolares sem o apoio da gestão local e sem o conhecimento que sustentasse a prática inclusiva.

Além disso, destacando este recorte da fala: "não se aceitava certa deficiência" verificamos o conceito de estigma, marcado pela identificação desacreditada da PcD. Segundo Goffman (1988) o estigma se estabelece substantivando as interações relacionais quando não há a aceitação social plena da pessoa (PcD). De fato, o estigma esteve presente na relação entre o "sistema" e a PcD, conforme o depoimento da professora Mariane, o que apontou que as regras do sistema escolar não são inclusivas, pois não aceitam a diferença do aluno com deficiência. Convém ressaltar que caberia ao sistema escolar a reversão ${ }^{5}$ do estigma perante a deficiência, criando um conjunto de procedimentos educacionais que eliminem as condições adversas da PcD, e inclua-a de forma igualitária no processo ensino-aprendizagem.

Dessa maneira, através do exemplo da fala da professora Mariane, observamos que a formação inicial dos professores deixou uma lacuna na orientação pedagógica de cunho crítico-reflexiva, o

\footnotetext{
${ }^{5} \mathrm{~A}$ reversão do estigma é possível quando há um conjunto de ações mutua das pessoas que se relacionam com a pessoa estigmatizada para atribuir na identidade social o valor real pessoal (COSTA, 2010).
} 


\section{6}

que lhes dificultou o enfrentamento das dificuldades para trabalhar na perspectiva da inclusão e expressarem dúvidas sobre como intervir com a PcD no momento delas passarem a fazer parte da escola regular.

Nesse sentido, em virtude da concepção adquirida na formação inicial, e reforçada ao longo do processo de atuação profissional, a visão tradicional fundamentada no esporte formal se refletiu na tematização do conteúdo na prática pedagógica. Com relação a esse aspecto, verificamos que os professores aceitam como meta suficiente para o aluno com deficiência, a sua aceitação pela turma; já, para o aluno sem deficiência almejavam como meta a aptidão motora, o rendimento. Os professores não conseguiam aceitar a prática docente de ensinar o aluno que não alcança o rendimento conforme o conjunto de regras sustentado pelo conteúdo disciplinar previsto no currículo tradicional. Observamos um exemplo dessa situação quando a professora Paula comentou sobre o planejamento de uma aula sem o foco no rendimento esportivo, disse ela: "Não, eu não acredito, o terceiro ano, quarto ano, tudo bem fazer uma aula mais passiva, mais moderada. Mas precisa dar aula agitada, necessitam o corre-corre, o agito, eles necessitam disso. E quando a Carol tá, eu não consigo fazer nada disso." (Professora Paula no Seminário 3 em 17/09/2010).

Carol é uma PcD que a professora não aceita na proposta da aula de rendimento esportivo. Nesta situação vimos a condição de desvio, pois a aluna com deficiência está fora das normas de conformidade, que a professora planejava para a aula. Segundo Goffman (1988) o desvio se estabelece quando as pessoas compartilham de um conjunto de regras e expectativas normativas, que estão presentes porque foram incorporadas, segregando os que a elas não se adéquam.

Com relação ao conteúdo da formação continuada sobre inclusão no contexto local, destacamos, como um caso ilustrativo do grupo, os comentários desta professora: "Não participei de nenhuma 
formação que me desse subsídios para trabalhar com inclusão, porém a necessidade faz com que eu mesma procure recursos para enfrentar este obstáculo" (Professora Paula na Oficina em 13/08/ 2010).

Os professores relataram a falta da formação continuada na perspectiva da inclusão, tendo recorrido ao senso comum ou a tentativa e erro da própria experiência, o que demonstrou o isolamento dos professores para abordar a concepção inclusiva no contexto local. Tal condição revelou que os professores se sentem impotentes, distantes da gestão e isolados na busca de ações inclusivas para as suas aulas de Educação Física. Segundo Falkenbach, Ordobas e Machado (2008) e Medeiros e Falkenbach (2008), os professores realmente sentem insegurança por medo e falta de preparo para atuar na perspectiva inclusiva. Daí justifica-se na literatura e nos dados apresentados neste estudo a importância de formar continuamente os professores a partir desse conceito.

Além disso, devemos considerar que o conjunto de procedimentos que asseguram o ensino inclusivo perpassa o imperativo de adaptações físicas, acessibilidade e tecnologias assistivas, avançando, de forma essencial, para a necessidade de formar e capacitar permanentemente os professores. Identificamos esse entendimento nesta fala do professor: "É, mas as pessoas acham que colocando a rampa e adaptação no banheiro, pronto! A escola já esta pronta!" (professor Rodrigo no Seminário 3 em 17/09/2010. O comentário acima demonstrou com angústia o isolamento dos professores e a falta de compreensão do sistema local para trabalhar a inclusão em sua plenitude. Para Mantoan (2003) é tarefa fundamental da escola inclusiva, formar e aprimorar continuamente o professor. Dessa maneira, observamos a carência dessa perspectiva de formação em todo o percurso de formação profissional dos professores, tanto na formação inicial, quanto continuada.

Ressaltamos que a inclusão não acontece pronta e que as ações didático-pedagógicas não estão descritas na literatura sob uma técnica padronizada que se possa seguir. Com base nessa idéia optamos 
pela proposta de trabalho na pesquisa-ação, para que os professores participantes adquirissem esta consciência na vivência das ações habituais das suas aulas de Educação Física. Contudo no processo deste estudo analisamos que boa parte das expectativas dos professores de Educação Física estavam direcionadas ao rendimento esportivo e ao desenvolvimento motor normal, nossa segunda categoria.

\section{RENDIMENTO ESPORTIVO E O DESENVOLVIMENTO MOTOR "NORMAL"}

Iniciamos a discussão desta categoria com o seguinte registro: "Bom no momento do chute do Sérgio [...] aproximei ele da trave, posicionei a bola para facilitar seu chute; [e] pra minha surpresa o goleiro simulou um frango a favor do Sérgio" (Professora Mariane no Diário de Campo em 16/08/2010). Em seu registro a professora demonstrou uma reação de surpresa quando o aluno sem deficiência (o goleiro) não demonstrou interesse na prática de caráter competitivo, sendo que, para o aluno o resultado competitivo não contava, mas para a professora Mariane sim, por isso o "frango" simulado a surpreendeu, o que denota que as expectativas estavam voltadas ao rendimento esportivo.

Na pesquisa-ação as ações inclusivas propostas nas aulas de Educação Física sofreram resistência para sua legitimação por parte dos professores que condicionaram suas práticas escolares pelos códigos do esporte; no entanto, os alunos demonstraram não estar impregnados dos significados de rendimento e concorrência esportiva. Nesse sentido, apresentamos o comentário da professora Paula:

Aí na hora do recreio dei bola, e os grandes jogando e o pequeno lá [fez gestos para pedir a bola]. Aí eles incluíram e excluíram ao mesmo tempo, porque colocaram ele [o pequeno] para jogar, mas a regra era: não podia acertar nele, e cada um tinha que passar uma vez a bola para ele. Aí ele chegou em

Movimento, Porto Alegre, v. 19, n. 03, p. 149-169, jul/set de 2013. 
casa e disse que a aula de Educação Física foi maravilhosa, não tinha nada haver comigo, foi no recreio. Mas ele chegou em casa falando da aula de Educação Física (Professora Paula no Seminário 3 em 17/09/2010).

É notável que os alunos criaram estratégias inclusivas e construíram as regras de um jogo competitivo, do futebol, não considerando as diferenças de desempenho entre os maiores e os menores como um limite. Por outro lado, a professora Paula sentiu que o aluno foi excluído, pois as regras do jogo foram adaptadas para o seu desempenho. Este conceito da professora revela a resistência para destituir-se das regras e normas da instituição esportiva na prática escolar, resistindo aos padrões do ensino inclusivo.

Tal conflito expressou o desafio para os professores: destituirse dos significados do esporte formal, para adequar os procedimentos da sua prática pedagógica para efetivar uma aula verdadeiramente inclusiva. Esta situação confere com os apontamentos de Bracht et al. (2002) sobre a identidade social que os professores de Educação Física, mais vinculada ao papel social de treinadores, e menos como professores ou educadores.

Se considerarmos o professor como um sujeito com formação adequada para orientar sua prática pedagógica no sentido da inclusão, podemos situá-lo no grupo dos informados, descrito por Goffman (1988). Isto é, como as pessoas que se relacionam com a pessoa estigmatizada e consideram-na como uma pessoas comum. Sob esta orientação os professores, nas relações com a PcD, devem ser os mediadores do processo de reversão do estigma da deficiência proporcionando ao aluno a aceitação social comum dentro do ambiente escolar. No entanto, os professores participantes almejavam as respostas dos alunos direcionados ao rendimento esportivo, e não respostas adequadas às possibilidades individuais. 


\section{ArtigosOrignais}

Chicon (2008) aponta que a prática educacional revela que os professores que viveram a orientação esportivista demonstram sinais até os dias atuais de não aceitação do aluno com deficiência e do aluno não habilidoso. Nesse sentido, confirmamos que as expectativas dos professores de Educação Física voltadas ao desenvolvimento motor normal, ansiavam que o aluno com deficiência realizasse condutas de ajustamento social ${ }^{6}$ para se adaptar e ter a capacidade de responder com habilidade à prática do esporte na escola, verificamos este pressuposto com a fala do professor João: "To pensando: o que eu vou fazer com o Luiz para ele jogar futebol?" (professora Mariane no Seminário 3 em 17/09/2010). O planejamento do professor visava adaptar o aluno ao ensino do futebol, ou seja, o professor na aula desejou que o aluno com deficiência realizasse ajustamento de conduta com relação à sua condição de deficiência, estigmatizando-o.

Para Goffman (1988) também cabe ao grupo dos informados a aceitação da pessoa estigmatizada como uma pessoa comum sem impor a necessidade de ajustamentos, conforme já citamos anteriormente. Desta forma, compreendemos que os professores, como membros do grupo dos informados, não podem impor que a PcD realize condutas de ajustamentos; portanto, os professores podem lecionar uma aula inclusiva executando procedimentos de adaptação do ensino para os alunos.

Contudo, boa parte das expectativas dos professores estavam direcionadas ao desenvolvimento motor normal, substantivando-os a desejar o ajustamento social da PcD. Na análise do estudo observamos que tal prática dos professores incidia sob a influência das características do sistema escolar local, nossa terceira categoria.

\footnotetext{
${ }^{6}$ Os ajustamentos sociais são estratégias que a pessoa estigmatizada é substantivada a utilizar para lidar com a condição de deterioração da sua identidade nas interações sociais (GOFFMAN, 1998).
} 


\section{SISTEMA dE AVALIAÇÃo do COMPONENTE CURRICULAR EduCAÇão FísICA E AS REORIENTAÇõES DA PRÁTICA PEDAGÓGICA}

A este respeito, pontuamos que a avaliação escolar local consistia em um procedimento padronizado implementado em todas as unidades escolares da rede municipal, que conceituava o desempenho do aluno em relação a diversas capacidades psicomotoras normais e era aplicado bimestralmente (sem permitir a redução da nota ou conceito), assumindo um caráter mais tecnocrático que reflexivo. Esse procedimento de avaliação subordinou as expectativas dos professores de Educação Física ao resultado de padrão ótimo, o que gerou uma discordância de parâmetros avaliativos técnicos que não asseguram a avaliação do ensino inclusivo, pois a inclusão conceitua-se no caráter reflexivo.

Para os professores esse conflito entre avaliar os resultados a partir de expectativas técnicas e atender aos princípios reflexivos da inclusão, criou um dilema. Mediante tal conflito, ressalvamos que os professores sentiram-se frustrados na avaliação dos resultados inclusivos, como observamos neste comentário: "Eu não sei. Eu tô tentando. Tem hora que eu me desmotivo. É que eu não vejo nada na Carol, nada, nenhuma resposta" (Professora Paula no Seminário 3 em 17/09/2010).

Notamos na fala anterior, que ilustra o sentimento do grupo, que os professores avaliaram o ensino inclusivo sob o padrão técnico de avaliação do contexto local. Esta forma de avaliação técnica presume que o resultado bimestral implica o domínio integral dos conhecimentos tematizados durante o período em questão, não permitindo abordar o domínio dos saberes relativos à inclusão. Dessa maneira, os resultados e as respostas das ações inclusivas foram reduzidos e anulados, pois a avaliação não era de caráter reflexivo.

Segundo Gramorelli e Neira (2009) a avaliação com enfoque quantitativo estratifica os alunos em aptos e inaptos, sendo que, tal procedimento leva aos professores a avaliarem elementos pouco afeitos à função da Educação Física escolar de promover a apropriação crítica das práticas corporais, no sentido de reproduzi- 
las e recriá-las. No processo da pesquisa-ação os professores realizaram as ações inclusivas propostas e planejadas, mas encontraram sérias dificuldades para legitimar a abordagem inclusiva, por conta dos processos de planejamento e avaliação fortemente ancorados no sistema educacional local.

No município a prática pedagógica da Educação Física escolar foi condicionada aos jogos escolares, os Jogos Recreativos Municipais Escolares e os Jogos Escolares, tanto que a seleção e sequenciação do conteúdo acompanha a ordem das competições das modalidades esportivas dos jogos municipais que são bimestrais. Frente a essas percepções, verificamos no percurso da pesquisa que os professores realizaram as ações inclusivas reorientadas com sucesso, mas apresentaram dificuldades para internalizar a concepção de inclusão, e afirmar esta abordagem como orientação legítima da prática pedagógica da Educação Física escolar, devido ao condicionamento do sistema educacional local para participar nas competições esportivas escolares. Situação semelhante revelou-se nos estudos de Bracht et al. (2002), que apresentaram uma proposta com os professores de Educação Física, de mudança na prática pedagógica a partir do método da pesquisa-ação e encontrou por parte dos participantes resistência à mudança para uma prática críticareflexiva, devido a influência da orientação tradicional.

Destacamos, ainda, que os professores participantes desta pesquisa realizaram com vontade o enfrentamento das barreiras para vencerem o desafio da mudança e atuarem na perspectiva da educação inclusiva na Educação Física, pois mesmo sem o reconhecimento da gestão local os professores alcançaram com sucesso ações inclusivas nas suas práticas pedagógicas, como descrevemos a seguir nesta escrita da professora: "Tirei o Marcos da cadeira para fazer rolamento, ele teve muita dificuldade, fez cara de choro, fizemos uma vez só e fiquei com medo de estar machucando ele, aí sentamos no tatame e fizemos alguns abdominais (a monitora ajudou), os outros alunos que também estavam nesta atividade também fizeram" (Professora Paula no Diário de Campo em 07/10/2010). 
Os dados revelaram uma postura de atitude inclusiva da professora segundo a reorientação das aulas na perspectiva inclusiva. No dado seguinte também verificamos a intervenção do professor e da monitora como mediadores para evitar o alinhamento intragrupal ${ }^{7}$ que aconteceu entre o aluno com deficiência (Pedro) e uma aluna com obesidade (Silvia), segundo o registro do instrumento de observação livre:

No circuito as crianças não interagiam com o Pedro o professor orientava: Estimulem o Pedro no circuito. A monitora falou: "Deixa ele Silvia, vai com os outros". Outra colega pegou na mão do Pedro e andaram um pouco no circuito, depois mais uma e logo Silvia veio e tirou a colega, pegando na mão dele, aquela que saiu, queixou-se: "Ah Silvia, eu tava ali!" A monitora orientou e caminharam os três juntos no circuito. (Observação Livre em 14/ 10/2010).

O professor Rodrigo e a monitora intercederam na aula inclusiva para impedir o alinhamento intragrupal, estimulando os demais alunos a favorecerem o alinhamento exogrupal. Para Goffman (1988) o alinhamento exogrupal está substantivado pelas relações habituais que manifestam a aceitação social plena da identidade real da pessoa com deficiência. Durante a pesquisa-ação priorizamos o alinhamento exogrupal nas aulas inclusivas de Educação Física.

Adiante ressaltamos que os professores se empenharam nas ações inclusivas, pois tal mudança mostrou-se nas falas dos professores, dentre as que destacamos: "Já ta mais produtivo [a aula inclusiva]. Não que antes não fazia, só que bem leiga, [...] Bem leiga, agora tô me fundamentando no que falamos, nos materiais" (Professora Mariane no Seminário em 17/09/2010).

A partir das descrições refletimos que a reorientação da ação docente, através da pesquisa-ação proporcionou novos significados

\footnotetext{
${ }^{7} \mathrm{~A}$ pessoa estigmatizada realiza o alinhamento intragrupal para se ajustar a sociedade. No alinhamento intragrupal o indivíduo estigmatizado relaciona-se com seus semelhantes (GOFFMAN 1988). A aluna Silvia estigmatizada devido a obesidade procurava se relacionar continuamente com o aluno Pedro, já que ele é um aluno com deficiência e não pertence ao grupo social dominante [os normais].
} 
à Educação Física inclusiva, possibilitou elaborar um planejamento adequado ao conceito de inclusão, e permitiu olhar com equidade para o aluno com deficiência. Cruz (2003) referiu em seu estudo que a mudança na prática pedagógica da Educação Física a partir da pesquisa-ação denotou com significância este aspecto, e os professores não se sentiram mais sozinhos, encorajando-se para dar o primeiro passo e enfrentar as angústias decorrentes das interações sociais e profissionais.

Nesse sentido, o grupo da pesquisa-ação contribuiu para perspectivar o trabalho futuro. Ilustramos isso nesta fala do professor:

O grupo me auxiliou para reavaliar a prática pedagógica e a reconstruir o planejamento para o próximo ano. Ajudou a melhorar e criar meios de desenvolver aulas inclusivas. Segundo o grande grupo, a inclusão deve ser um processo amplo em que eu possa transformar promovendo uma aceitação e valorizando as diferenças (Professor Rodrigo no Grupo Focal em 19/11/2010).

Como falaram os professores: as conquistas da pesquisa-ação promoveram a conscientização com relação ao aluno com deficiência e o planejamento da prática pedagógica da aula inclusiva. Entretanto, orientados pelas expectativas de resultados esportivos, o grupo permaneceu com a dificuldade de avaliar as potencialidades e as respostas dos alunos com deficiência, pois comparam o resultado da inclusão ao rendimento esportivo tradicional. Segundo Rechineli, Porto e Moreira, (2008), a Educação Física referenciada no princípio da diversidade possibilita ao professor trabalhar as diferenças dos alunos com deficiência no sentido de re-significá-las e respeitá-las, não devendo mais possibilitar a aprendizagem do movimento no privilégio de conteúdos esportivos e na realização de exercícios tradicionais. Para sustentar esta reflexão apresentamos a fala da professora Mariane que sugere o privilégio do esporte e a dificuldade de validar o resultado da prática inclusiva: "Na inclusão a visão é ampla e o resultado é uma incógnita!" (Professora Mariane no Grupo Focal em 29/11/2010). 


\section{Considerações FinaIS}

Os dados revelaram a sensibilização do professor sobre a prática pedagógica inclusiva na Educação Física escolar. Destacamos que houve um processo de reflexão-ação por parte dos professores que começaram a mudar aspectos de sua prática com inserções de procedimentos para a inclusão do aluno com deficiência nas suas aulas. Porém, não sabemos dimensionar se as conquistas garantem a legitimação da concepção inclusiva de forma permanente.

Quanto ao estigma do aluno com deficiência, não encontramos ações institucionais dispostas a proporcionar a reversão desta condição, pois os professores trabalharam sozinhos na reorientação da Educação Física escolar, na perspectiva da inclusão, sem o reconhecimento e o apoio da gestão local.

Os códigos da instituição esportiva balizaram a Educação Física escolar como principal conteúdo e como parâmetro para a avaliação do alunado no contexto local. Desta forma, os professores experienciaram o dilema entre a fundamentação do ensino inclusivo de respeitar as individualidades e as potencialidades dos alunos e os códigos do esporte, o que foi reforçado pela formação inicial orientada por esse paradigma, e pela falta de formação continuada orientada pela concepção inclusiva no contexto local.

As expectativas dos professores relacionadas à inclusão escolar estavam voltadas ao rendimento esportivo e ao desenvolvimento motor "normal", pois na prática docente eles tiveram dificuldades em reconhecer as diversas respostas dos alunos com deficiência, alegando não haver resultados ou haver resultados mínimos na inclusão.

Apontamos a necessidade e possibilidade de novas pesquisas sociais para subsidiar o desenvolvimento da reorientação das diretrizes pedagógicas para a Educação Física escolar na rede escolar investigada, em particular no que diz respeito ao sistema de avaliação, na gestão do trabalho na área da educação escolar inclusiva, e na reversão do estigma do aluno com deficiência. 
166 ArtigosOrignais Gisele Cristina de Souza, Santiago Pich

E finalmente consideramos que, mesmo frente a um contexto hostil, os professores se sensibilizaram da importância de trabalhar na perspectiva da educação inclusiva e iniciaram um processo de reorientação da sua prática pedagógica, iniciando o caminho no sentido da reversão do estigma. 
The guidance action teaching in Physical Education under the perspective of inclusion: action research as a way

Abstract: This article researched the inclusion in physical education, guided by the theory of stigma of the persons with disabilities. The aim was to guide the process of reconstruction of the pedagogical practices of teachers in implementing the inclusive physical education. We used a qualitative approach in social research with a proposal of action-research. The content analysis resulted in three categories: the legacy of the graduation and in-service training about inclusion; the sport performance and the "normal" motor development; and the evaluation system of the physical education and the reorientation of the pedagogical practice.

Keywords: Physical Education. Inclusion. Practice Pedagogic. Action-research.

La reorientación de la acción pedagógica en la Educación Física bajo la perspectiva de la inclusión: la investigación-acción como camino Resumen: El artículo aborda la inclusión escolar en la Educación Física, bajo el referencial del estigma de la persona con deficiencia. El objetivo fue orientar el proceso de reconstrucción de las prácticas pedagógicas del profesor en la implementación de la Educación Física inclusiva. Adoptamos el abordaje cualitativo de investigación con la propuesta de la investigación-acción. El análisis de contenido resultó en tres categorías: el legado de la formación inicial y continuada sobre la inclusión; el rendimiento deportivo y el desarrollo motor "normal"; y el sistema de evaluación del componente curricular educación física y las reorientaciones de la práctica pedagógica.

Palabras-clave: Educación Física escolar. Inclusión. Práctica Pedagógica. Investigación-acción. 


\section{REFERÊNCIAS}

AGUIAR, João S.; DUARTE, Edson. Educação inclusiva um estudo na área da Educação Física. Revista Brasileira de Educação Especial, Marília, v. 11, n. 2, p. 223-240, maio/ago. 2005.

ANTUNES, Celso. Educação Inclusiva: disfunções cerebrais e a inclusão. Florianópolis: CEITEC, 2006.

BARDIN, Laurence. Análise de conteúdo. Tradução Luís A. Reto; Augusto Pinheiro. 3. ed. Lisboa: Edições 70, 2004.

BETTI, Irene C. R; BETTI, Mauro. Novas perspectivas na formação profissional em Educação Física. Motriz, São Paulo, v. 2, n. 1, p. 10-15, jun. 1996.

BRACHT, Valter. Educação Física e aprendizagem social. Porto Alegre: Magister, 1992.

A constituição das teorias pedagógicas da Educação Física. Cadernos Cedes, Campinas, v. 19, n. 48, p. 69-88, ago. 1999.

BRACHT, Valter et al. A prática pedagógica em Educação Física: a mudança a partir da pesquisa-ação. Revista Brasileira de Ciências do Esporte, Campinas, v. 23, n. 2, p. 9-29, jan. 2002.

CAPARROZ, Francisco E. Entre a Educação Física na escola e a Educação Física da escola. 3. ed. Campinas: Autores Associados, 2007.

CHICON, José F. Inclusão e exclusão no contexto da Educação Física escolar. Movimento, Porto Alegre, v. 14, n. 1, p. 13-38, jan./abr, 2008.

COSTA, Alberto M.; SOUZA, Sônia B. Educação Física e esporte adaptado: história, avanços e retrocessos em relação aos princípios da integração/inclusão e perspectivas para o século XXI. Revista Brasileira Ciência e Esporte, Campinas, v. 25 , n. 3 , p. 27-42, maio 2004.

COSTA, Fernanda B. N. Prostituição, Maternidade e Infância. Escolinha Comunitária Nilton Guedes: uma busca por cidadania e reversão do estigma de prostitutas e seus filhos (1988-1997). In: ENCONTRO REGIONAL DAASSOCIAÇÃO NACIONAL DE HISTÓRIA: RIO MEMÓRIA E PATRIMÔNIO, 14., 2010, Rio de Janeiro. Anais... Rio de Janeiro: UniRio, 2010.

CRUZ, Gilmar C. Prática reflexiva de professores de Educação Física ante o desafio da inclusão escolar de alunos com necessidades educacionais especiais. In: CONGRESSO BRASILEIRO DE CIÊNCIAS DO ESPORTE, 13., 2003, Caxambu. Anais... [s.n.t.].

FALKENBACH, A. P.; ORDOBAS, A. C. M.; MACHADO, G. S. Experiências de inclusão de professores da Educação Física na escola comum: a relação professor/aluno 
com necessidades especiais. Revista Digital, Buenos Aires, v. 13, n. 126, nov. 2008.

GOFFMAN, Erving. Estigma: notas sobre a manipulação da identidade deteriorada. Tradução Maria B. M. L. Nunes. 4. ed. Rio de Janeiro: Guanabara koogan, 1988.

GRAMORELLI, Lilian C.; NEIRA, Marcos G. Dez anos de parâmetros curriculares nacionais: a prática da Educação Física na visão de seus autores. Movimento, Porto Alegre, v. 15, n. 4, p. 107-126, out./dez. 2009.

MANTOAN, Maria T. E. Inclusão escolar: o que é? por quê? como fazer?. São Paulo: Moderna, 2003.

MEDEIROS, J.; FALKENBACH, A.P. A relação professora/aluna com necessidades especiais nas aulas de Educação Física da escola comum. Revista Lecturas: Educación Física y Deportes, Buenos Aires, v. 12, n. 117, fev. 2008.

OLIVEIRA, Ivanilde A. Espaço escolar: território de construção de representações e identidades. Trilhas, Belém, v. 1, n. 2, p. 56-65, nov. 2000.

PUPPIN, Andrea B. Da atualidade de Goffman para a análise de casos de interação social: deficientes, educação e estigma. Revista Brasileira de Estudos Pedagógicos, Brasília, v. 80, n. 195, p. 244-261, maio/ago. 1999.

RECHINELI, Andréa; PORTO, Eliane T. R.; MOREIRA, Wagner. Corpos deficientes, eficientes e diferentes: uma visão a partir da Educação Física. Revista Brasileira de Educação Especial, Marília, v. 14, n. 2, p. 293-310, maio/ago. 2008.

SASSAKI, Romeu K. Inclusão: construindo uma sociedade para todos. Rio de Janeiro: WVA, 1997.

THIOLLENT, Michel. Metodologia da pesquisa-ação. 7 ed. São Paulo: Cortez, 1996.

Endereço para correspondência:

Universidade Federal de Santa Catarina (UFSC)

Departamentos de Estudos Especializados em Educação (EED)

Centro de Ciências da Educação (CED)

Campus Universitário Reitor João David F. Lima

Trindade - Florianópolis - SC - Brasil

Cx. Postal: 476 - CEP: 88040-900

Recebido em: 22.11.2012

Aprovado em: 03.03.2013

Movimento, Porto Alegre, v. 19, n. 03, p. 149-169, jul/set de 2013. 